\title{
Possibilities of using welding-on technologies in crane wheel renovation
}

\author{
J VIŇÁŠ and L KAŠČÁK \\ Department of Technology and Materials, Faculty of Mechanical Engineering, Technical University of Košice, \\ Slovakia
}

MS received 26 September 2007

\begin{abstract}
The paper deals with analysis of welds-on quality of traverse crane wheels made from gr. 90-60 material, ASTM A148. Three types of welding-on technology with various filling materials were used. On wheel after wearing was welded-on one interlayer by a combination of additional materials, wire A 106 with $F 11$ addition and two cover layers made by a combination of $A 508$ wire with $F 13$ addition. Wheel surface was hardened after welding-on to a depth of $3 \mathrm{~mm}$. A second welds-on technology was a combination of A 106 wire with F 11 addition. Two cover layers were made by a combination of RD 520 wire with $F 56$ addition. Third welds-on technology was realized to face one layer by $\mathrm{C} 113$ wire in inert atmosphere: $80 \% \mathrm{Ar}+20 \% \mathrm{CO}_{2}$. Two cover layers were made by wire with self protect Lincore 40-O. Properties of renovated traverse crane wheels were compared with the properties of new wheels with surface hardened layer. The welds-on were exposed to adhesive wearing where surface resistance was examined according to their weight loss. Influence of a particular element on the welds-on chemical composition was examined by EDX analyses.
\end{abstract}

Keywords. Traverse crane wheel; weld-on; weld-on wire; wearing.

\section{Introduction}

The most common causes of machine component parts and structures breakdowns are tribological processes that take place in functional surfaces. That is the reason why tribological characteristics of used materials are of great significance for proper functioning of machine component parts and structural elements. Interaction of functional surfaces in relative motion results in unwanted changes in surface layers and their wear and tear (Bhansali 1980; Limmaneevichitr and Kou 2000; Kou 2003).

Renovation was applied as a method which financially favoured maintenance of machines and operational equipment. A variety of different technologies is used in renovation, which enable recovery of machines or in some cases help prolong machine service life. Traverse crane wheels in engineering practice are exposed to significant wear as a result of their high surface compression stress. It is expensive to replace worn out wheels by new ones, and hence efforts were made to prolong their service life as long as possible (Matsuda et al 1980; Limmaneevichitr and Kou 2000).

This paper deals with the possibility of renovation of traverse crane wheels by welding-on technology and evaluation of welded-on layers in demanding tribological conditions. The aim is to compare the quality of welds-on carried out with addition and in protective gas atmos-

\footnotetext{
*Author for correspondence (jan.vinas@tuke.sk)
}

pheres, to find out the influence of structures and mixing of different layers on adhesive wear resistance, to analyse the results of weld-on tests with properties of new traverse wheels and based on the results to recommend suitable welding-on technology of wheel renovation and their heat treatment, to recommend changes to the present situation in wheel welding-on.

\section{Used materials}

The examined traverse crane wheels were manufactured from the material gr. 90-60, ASTM A148 and its chemical composition is given in table 1 and its mechanical properties in table 2 .

This is a ferritic-pearlitic carbon steel for cast products, which is generally used for higher pressures and stress. Crane wheels roll along the rails manufactured from steel class ČSN 410425 - structural steel without guaranteed chemical composition with strength limit, $R_{\mathrm{m} \text { min }}=420 \mathrm{MPa}, \mathrm{S}$ content is $\max .0 .050 \%$ and $\mathrm{P}$ content is $\max .0 \cdot 050 \%$. Hardness number, $230 \mathrm{HV}$, corresponds to the given strength limits.

\section{Use of renovation technology and filling materials}

I. Welding-on technology (SAW) with addition:

Interlayer: weld-on wire A 106 of diameter $\phi=3.2 \mathrm{~mm}$ addition $\mathrm{F} 11$

Cover layer: weld-on wire A 508 of diameter $\phi=3.2 \mathrm{~mm}$ addition $\mathrm{F} 13$ 
Table 1. Chemical composition of material gr. 90-60, ASTM A148.

\begin{tabular}{lcccccc}
\hline Chemical elements & $\mathrm{C}$ & $\mathrm{Mn}$ & $\mathrm{Si}$ & $\mathrm{P}_{\max }$ & $\mathrm{S}_{\max }$ & $\mathrm{P}+\mathrm{S}$ \\
\hline$\%$ & $0.40-0.50$ & $0.40-0.80$ & $0.20-0.50$ & 0.050 & 0.050 & $\max .0 .090$ \\
\hline
\end{tabular}

Table 2. Mechanical properties of material gr. 90-60, ASTM A148.

\begin{tabular}{cccccccc}
\hline Mechanical properties & $R_{\mathrm{e} \min }[\mathrm{MPa}]$ & $R_{\mathrm{m} \min }[\mathrm{MPa}]$ & $A_{5 \min }[\%]$ & $Z_{\min }[\%]$ & $K C U_{\min } 3\left[\mathrm{~J} \cdot \mathrm{cm}^{-2}\right]$ & Hardness, HV & $E[\mathrm{GPa}]$ \\
\hline 300 & $590-740$ & 12 & 15 & 20 & $173-214$ & $209 \cdot 4$ \\
\hline
\end{tabular}

II. Welding-on technology (SAW) with addition

Interlayer: weld-on wire A 106 of diameter $\phi=3.2 \mathrm{~mm}$ addition $\mathrm{F} 11$

Cover layer: weld-on wire RD 520 of diameter $\phi=3.2 \mathrm{~mm}$ addition $\mathrm{F} 56$

III. Welding-on technology with wire in inert atmosphere (GMAW)

Interlayer: weld-on wire C 113 of diameter $\phi=2 \mathrm{~mm}$ inert atmosphere of mixed gas

(Ar 80\% + $\left.\mathrm{CO}_{2} 20 \%\right)$

Cover layer: weld-on wire Lincore $40-\mathrm{O}$ of diameter $\phi=2 \mathrm{~mm}$.

Welding-on of worn-out wheels having a diameter of $\phi$ $800 \mathrm{~mm}$ was carried out first by creating one interlayer and subsequently by two cover layers. Preheating of the examined crane wheels was carried out by rotation of gas burner to a temperature of $180-250^{\circ} \mathrm{C}$ with a heating speed of $300^{\circ} \mathrm{C} \cdot \mathrm{h}^{-1}$. Cylinder parts of the wheels were weldedon in screw shifting the caterpillar by $1 / 3$ of its width. Wheel dimensions were adjusted by welding-on to the original dimensions with surplus material for machining. After welding-on the wheels were renovated using techno$\operatorname{logy} \mathrm{I}$, i.e. by isothermal annealing in the induction furnace which was preheated to a temperature of $800-840^{\circ} \mathrm{C}$. After heating the wheels to a temperature of $840^{\circ} \mathrm{C}$, they were cooled to a temperature of $620^{\circ} \mathrm{C}$ with subsequent holding for 2-3 h. After the wheels had been removed from the oven they were cooled in open air. After cooling, the wheels were machined by cutting operation to the required parameters and then the weld-on was hardened on the surface. Surface hardening was carried out by flame $\mathrm{C}_{2} \mathrm{H}_{2}+\mathrm{O}_{2}$. After heating by burner the weld-on was cooled by water spray. The thickness of the hardened layer was a maximum, $3 \mathrm{~mm}$. In the second and third renovation technologies the cover layer was not hardened on the surface. Technological parameters of welding-on are given elsewhere (Viňáš 2004).

\subsection{Reference material}

After welding-on the renovated crane wheels were compared with a new wheel manufactured from material gr.
90-60, ASTM A148 and its chemical composition is given in table 1 . The contact area and tire of the new wheel were hardened by $\mathrm{C}_{2} \mathrm{H}_{2}+\mathrm{O}_{2}$ on the surface while the wheel was rotating. Hardening temperatures for gr. 90-60, ASTM A148 were in the range from $870-890^{\circ} \mathrm{C}$. The depth of thorough hardening of the material was $3 \mathrm{~mm}$.

\section{Technique of experimental testing}

\subsection{Technique of structural and EDX analysis}

Structural analysis of individual welded-on layers was carried out on cross scratch patterns of the examined samples. Structure evaluation as well as photo documentation were carried out by means of the light microscope, ZEISS NEOPHOT II and electron-scanning microscope, Hitachi S-450. Chemical analysis of single weld-on layers and their transitional phases was carried out by the energy dispersive spectrometer, JEOL JSM-35 CF and LINK AN 10000 analyser.

\subsection{Technique of weld-on hardness evaluation}

Tests of weld-on hardness and the reference material were carried out in compliance with standard STN EN 1043-1 on test samples taken mechanically without heat treatment in accordance with standards, ISO 6507-1 and ISO 6507-2. The samples were taken from renovated traverse wheels from the region of the wheel and rail interface. The test was carried out by the testing machine, HPO 250. Hardness values were measured on scratch patterns in direction from the wheels and rails interface to the basic wheel material. Line a ran through the cut section of the tire of the examined wheel and line $b$ ran through the horizontal part of the wheel as shown in figure 1.

\subsection{Technique of weld-on microhardness evaluation}

Microhardness of individual weld-on layers and transient phases was measured on transverse scratch patterns of the taken samples in accordance with STN EN 1043-1. The test was carried out by the testing machine, SHIMADZUDUH 202. The applied load was $0.01 \mathrm{~N}$ and load time was $5 \mathrm{~s}$. 
Sample marking:

A samples : weld-on made by a combination of A 508 wire with $\mathrm{F} 13$ addition with an interlayer created by $\mathrm{A} 106$ wire with $\mathrm{F} 11$ addition;

R samples : weld-on made by a combination of $\mathrm{RD}$ wire with $F 56$ addition with an interlayer created by $\mathrm{A} 106$ wire and $\mathrm{F} 11$ addition;

L samples : weld-on made by a combination of Lincore 40-O with an interlayer created by $\mathrm{C} 113$ wire in gas $\left(\mathrm{Ar}+\mathrm{CO}_{2}\right)$.

\subsection{Technique of adhesive wear evaluation}

Crane wheels in technical practice are strained by high surface pressure, which results in different types of wear and tear. In assessing mutual interaction of the wheel and the rail it is necessary to consider mainly the type of wear and tear that results from their mutual contact and movement. Adhesive wear of the examined materials was tested by AMSLER machine with area contact, which enables dry testing of sliding pairs. Plates were made from the examined materials and the disc from ČSN 410425 steel (rail material). Bedding on the disc and the plate was adjusted to the pressure in the contact surface by compressing the spring by load $1.5 \mathrm{kN}$. The steel disc rotated at a speed of $200 \mathrm{revs} / \mathrm{min}^{-1}$. The size of adhesive wear was evaluated based on weight changes of the tested samples in individual phases of the experiment for a period of $30 \mathrm{~s}^{-1}$ and until seizure of the kinematics pair.

\section{Results and discussion}

\subsection{Hardness and microhardness measurement}

Maximum hardness values were discovered in places closest to the functional surface of tested samples in both examined directions. The obtained results indicated that the highest hardness was in new tranverse crane wheels

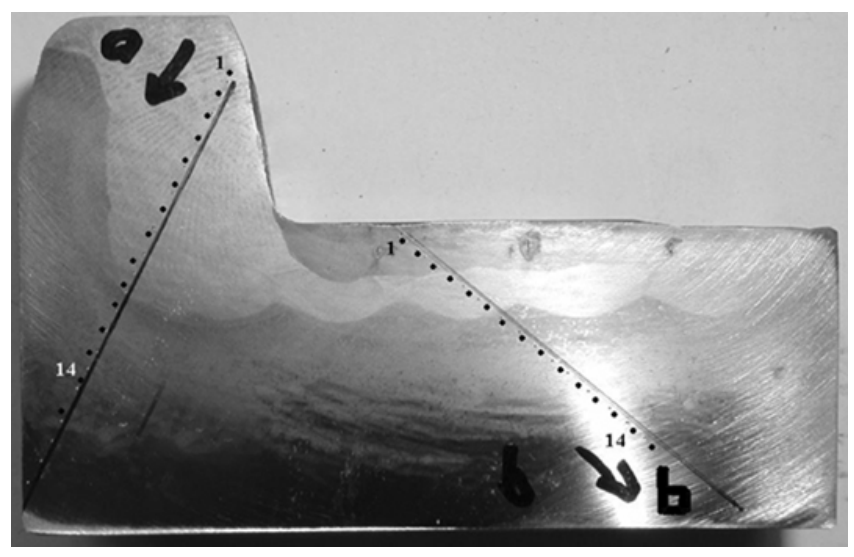

Figure 1. Hardness measuring on tested samples. with surface hardening in which the maximum values were between $669 \mathrm{HV} 10$ and $703 \mathrm{HV}$ 10. In wheels, which were renovated by welding-on, the measured hardness values were lower. The highest hardness value of all the evaluated welds-on was found in the weld-on made by A 508 wire with $\mathrm{F} 13$ addition where the maximum hardness value was $459 \mathrm{VH} 10$ in the cover layer that could be reasoned by welds-on heat treatment - hardening. By applying the second technique, the maximum hardness amounted to $446 \mathrm{HV} 10$ and in the third welding-on technology the maximum hardness amounted to $442 \mathrm{HV} 10$ in the cover layer of the weld-on (Viňáš 2004).

In individual samples marked A, R, L, microhardness values of $\mathrm{HV} 0 \cdot 10$ were observed. The highest values were measured in cover layers of welds-on. In A type samples the microhardness value amounted to $475 \mathrm{HV} 0.01$ as a result of hardening of the crane wheel cover layer. Values of weld-on microhardness in $\mathrm{R}$ and $\mathrm{L}$ type samples were somewhat lower and it was without application of wheel heat treatment after welding-on.

In the interlayer area there were more distinctive differences mainly in $R$ and $L$ type samples. The value measured in A type samples was close to values in R type samples. It could be because of application of the same filling materials for welding-on of the interlayer (A 106 wire with $\mathrm{F} 11$ addition). It is obvious that the interlayer made by $\mathrm{C} 113$ wire in the protective atmosphere of gases had lower strength properties than the layer in the abovementioned A and R samples. The lowest microhardness values were found in the area of base material not affected by heat.

\subsection{Metallographic and EDX structure analysis}

Chemical analysis of elements was carried out on samples with welds-on and from reference material according to the above-mentioned technique. Rail microstructure was open-grain pearlitic structure with minimum content of ferrite. The resulting structures of the individual layers of welds-on are shown and described in figures 2-4 (Viňáš 2004)

Figure 2 shows the weld-on microstructure made by technology I. Since the weld-on was not heat treated, a surface-hardened layer can be observed in the upper layer. It is a fine-grained acicular ferritic structure confirmed by hardness measurement, which amounted to $460 \mathrm{HV}$ 10. The structure was continuously changing depending on the distance from the surface into bainitic structure. In the cover layers there were diffused soft chromium carbide particles confirmed by EDX analysis. At the same time, the weld-on showed the presence of elements $\mathrm{Mn}$ and $\mathrm{Si}$ from filling material A 508, on the other hand, it was also affected by application of siliceous manganese addition $\mathrm{F}$ 13. The interlayer structure can be identified as bainitic, in some regions ferritic-pearlitic structure was observed to 

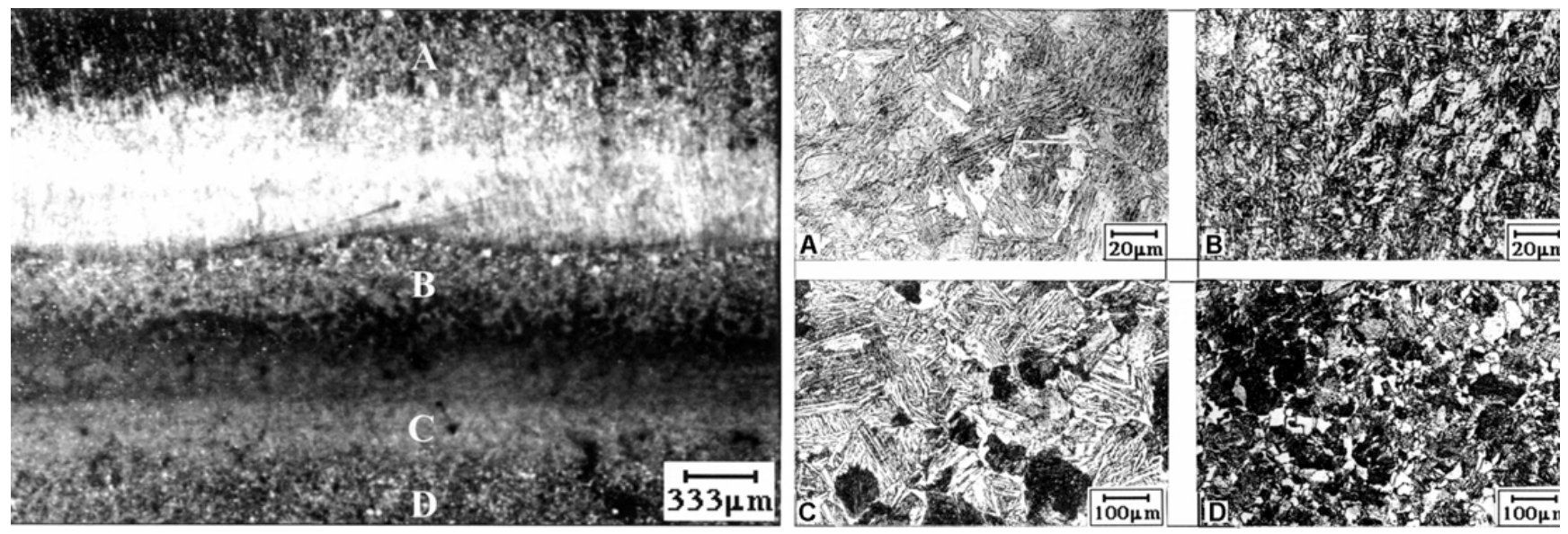

Figure 2. Structures of welds-on made by a combination of wire A 508 with F 13 addition, with interlayer made by A 106 wire with F 11 addition: A. Bainitic structure, cover layer detail, A 508 wire with F 13 addition, B. bainitic structure, interlayer detail made by A 106 wire and F 11 addition, C. acicular ferritic-pearlitic structure, detail of heat-affected zone with interlayer and base material and D. ferritic-pearlitic structure of base material gr. 90-60, ASTM A148.
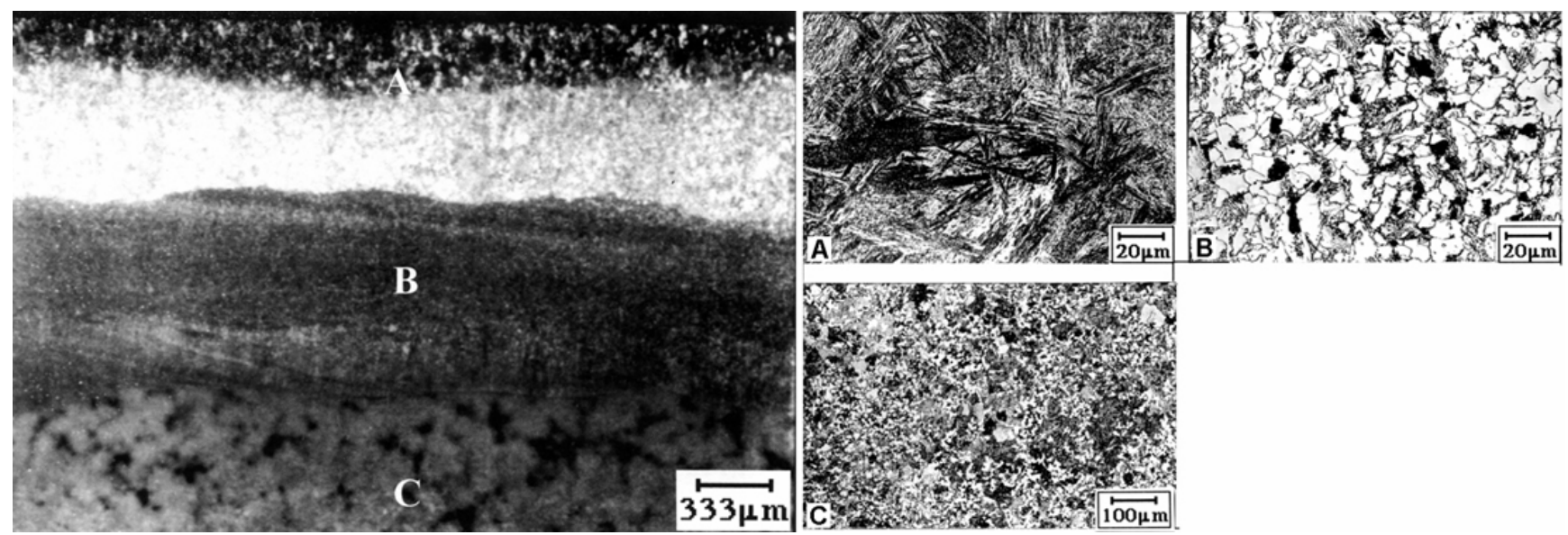

Figure 3. Structures of welds-on made by a combination of wire RD 520 with F 56 addition, with interlayer made by A 106 wire with F 11 addition: A. Bainitic structure, cover layer RD 520 wire and F 56 addition, B. ferritic-pearlitic structure, interlayer detail made by A 106 wire and F 11 addition and $\mathbf{C}$. ferritic-pearlitic structure of base material.
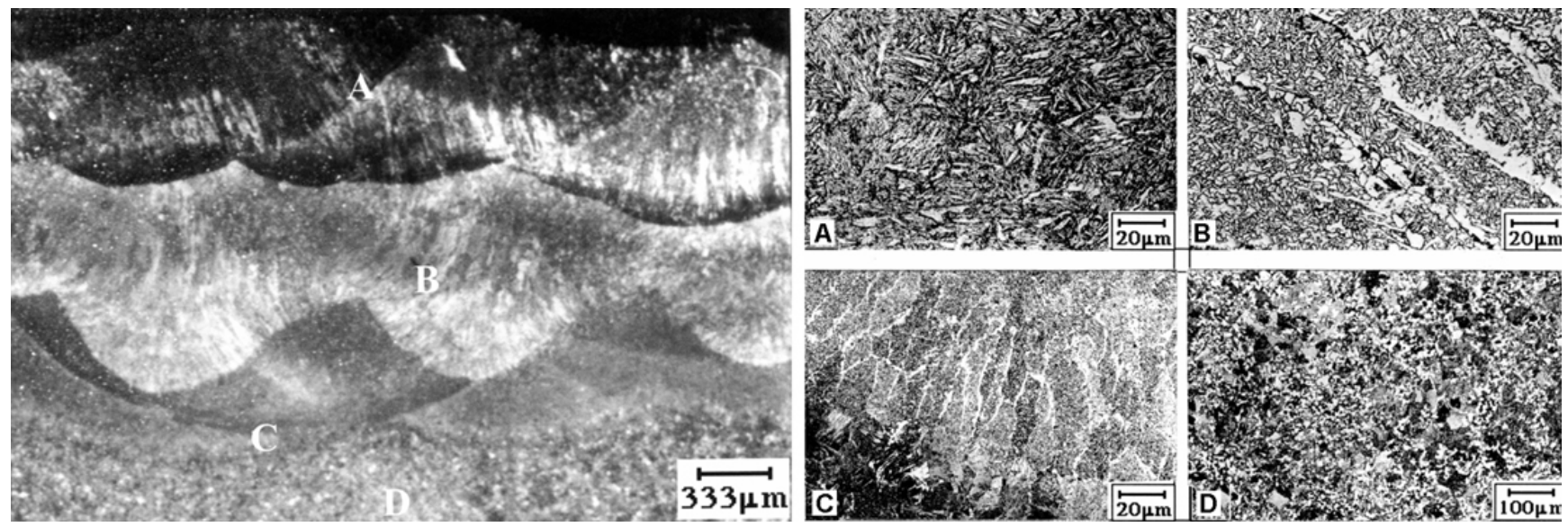

Figure 4. Structures of welds-on made by a combination of wire with its own protection Lincore 40-O, interlayer made by wire C 113 in inert atmosphere, $80 \% \mathrm{Ar}+20 \% \mathrm{CO}_{2}:$ A. Fine-grained acicular ferritic structure, cover layer Lincore $40-\mathrm{O}$ wire, B. ferritic structure with ferritic grain netting segregated on primary grain boundaries, interlayer detail made by C 113 wire in protecting gas, C. heat-affected zone between interlayer and base material and D. ferritic-pearlitic structure of base material gr. 90-60, ASTM A148. 

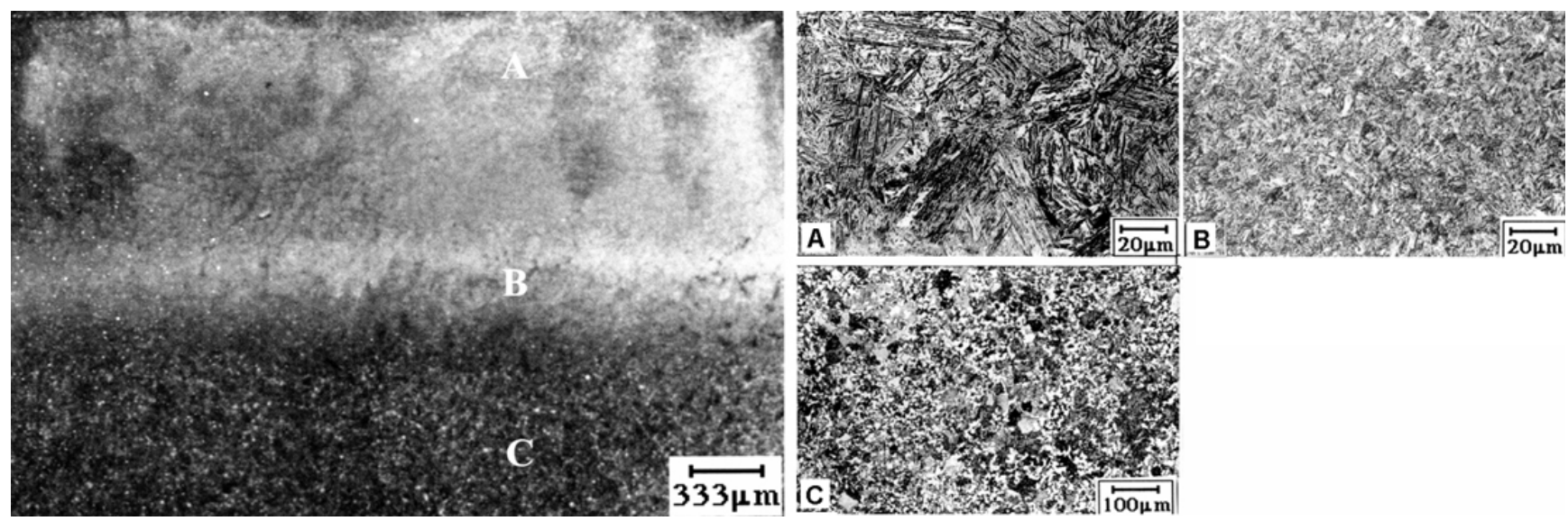

Figure 5. Structures of hardened crane wheel: A. Fine-grained martensitic microstructure of hardened layer of wheel, B. bainitic structure in heat-affected zone between hardened layer and base material and $\mathbf{C}$. ferritic-pearlitic structure of base material gr. $90-$ 60, ASTM A148.

gradually change into bainitic structure as confirmed by microhardness measurement in this area. The interlayer thickness was $\sim 2 \mathrm{~mm}$. Chemical analysis of the interlayer showed a decrease in the amount of the alloying elements in comparison with the cover layer. The decrease in the amount of the above-mentioned elements depends on the mixing of individual layers of welds-on. The area between the interlayer and the base material affected by heat is composed by open-grain acicular ferritic-pearlitic structure and as a result of heat treatment, grains grew and became thicker. Continuous growth and transformation of pearlite into bainite were obvious. In the structure there also occurred plate ferrite and on grain boundaries there were visible cement phases.

Figure 3 shows microstructure of the weld-on made by technology II. Microstructure of cover layers up to $3.5 \mathrm{~mm}$ from the surface is created by martensitic structure with acicular and plate-shaped formations. Bainitic structure was confirmed by hardness and microhardness tests. EDX analysis showed the presence of alloying elements such as $\mathrm{Cr}$ and $\mathrm{Si}$ in the cover layers of the weld-on but in the weld-on itself the most abundant alloying element was $\mathrm{Mn}$. These alloying elements were added to the weld-on from filling material, RD 520; there was also a considerable role played by the applied addition of $\mathrm{F} 56$ in alloying the weld-on. The interlayer structure is formed by ferritic-pearlitic structure, in which bainitic transformations can be observed. As a result of heat effect over temperature, $\mathrm{A}_{\mathrm{Cl}}$, the grains became thicker. The interlayer thickness is $\sim 2 \mathrm{~mm}$. Chemical analysis of the interlayer shows relatively continuous decrease of the alloying elements $\mathrm{Mn}$ and $\mathrm{Si}$ in comparison with cover layers. It is caused by lower amount of alloying elements in filling materials used for welding-on the interlayer. The decrease in $\mathrm{Cr}$ content in the interlayer was due to the absence of this element in the filling material, A 106. Its content in the interlayer decreases depending on the mixing of weldedon layers.

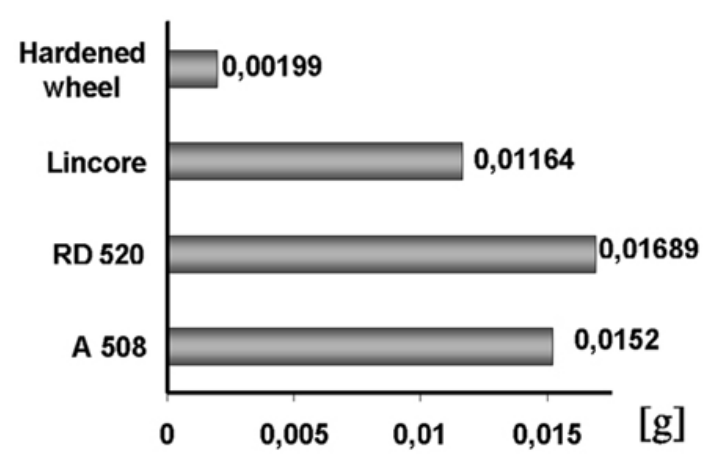

Figure 6. Course of adhesive wear after $30 \mathrm{~s}$.

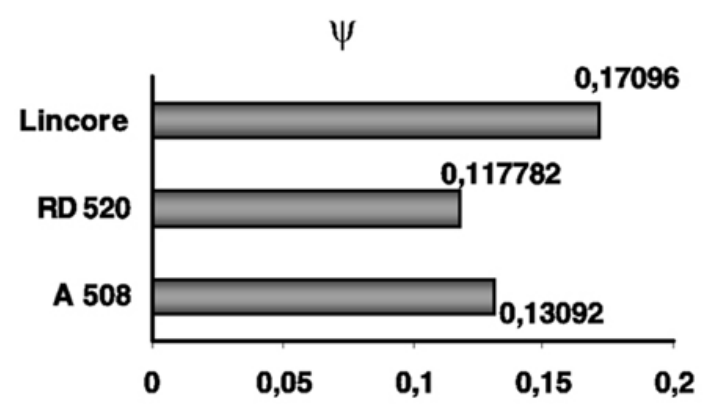

Figure 7. Relative weight wear of examined materials.

Figure 4 shows the microstructure of a weld-on made by technology III. The microstructure shows a distinct pattern of weld beads. The cover layers are made up of soft acicular ferritic structure in which the diffused soft grains of chromium carbide are confirmed by the weld-on chemical analysis. The presence of acicular ferritic structure was confirmed by hardness (maximum value was $442 \mathrm{HV} \mathrm{10)}$ and microhardness evaluation. EDX analysis shows that the $\mathrm{Cr}$ content in the weld-on in the area of cover layers was the highest, the content of $\mathrm{Mn}$ and $\mathrm{Al}$ in the weld-on was somewhat lower (Viňáš 2004). 
Si had the lowest content in the cover layer of the weld-on. The interlayer is created predominantly by softgrained ferritic structure. The interlayer thickness was $2.0 \mathrm{~mm}$. Chemical analysis of the interlayer showed that a decrease in the content of individual alloying elements in this area was continuous with the exception of the elements, $\mathrm{Cr}$ and $\mathrm{Al}$, which are not contained in the filling material of $\mathrm{C} 113$ wire. The details of metal microstructure in the transition area between the interlayer and the base material show bainitic structure. On grain boundaries, segregation of cementite was observed. The area of base material treated by heat is relatively small $(\sim 1.5 \mathrm{~mm})$.

Figure 5 gives evidence of the hardened wheel structure. The microstructure up to $3 \mathrm{~mm}$ deep from the surface was created by soft-grained martensitic structure with acicular formations. The microstructure contained no carbidic particles. Martensitic structure was also confirmed by hardness and microhardness test in which the values $700 \mathrm{HV}$ and $790 \mathrm{HV} \mathrm{0.01}$ were measured in comparison with hardness of welded-on layers which amounted to $470 \mathrm{HV}$ and $480 \mathrm{HV} 0.01$. In the area treated by heat there was soft-grained bainitic structure; its content was changing continuously with respect to its treatment by heat. Bainitic structure was close to the influence of hardening temperatures, it contained numerous martensitic phases and the transition area between the base material showed continuous grain thickening of the structure, growth and transformation of pearlite into bainite. The heat-affected zone was $2 \cdot 2 \mathrm{~mm}$ wide.

\subsection{Adhesive wear tests}

The lowest weight losses in the evaluated materials were found in samples taken from the hardened wheel made from gr. 90-60, ASTM A148 material (figure 6). The value of weight loss was $0.00199 \mathrm{~g}$ per sample. The reason for low weight losses was the hardened surface of the material and soft-grained martensitic structure highly resistant to adhesion. The lowest weight losses from the evaluated samples with welds-on as well as the longest times till seizure of friction pairs were measured in samples taken from wheels welded-on by Lincore 40-O wire. Adhesion resistance in this case was influenced by presence of $\mathrm{Cr}$ and its carbides in the friction layer as well as certain influence it had by the presence of Al. Respective weight wear and tear is shown in figure 7 (Viňás 2004)

\section{Conclusions}

This paper deals with the possibility of traverse crane wheels renovation aimed to prove suitability of examined filling materials in demanding tribological conditions. Properties of welded-on layers were evaluated and compared with the properties of new surface-hardened wheels manufactured from gr. 90-60, ASTM A148 material.

Chemical composition of welds-on carried out in traverse scratch patterns in the direction from base material
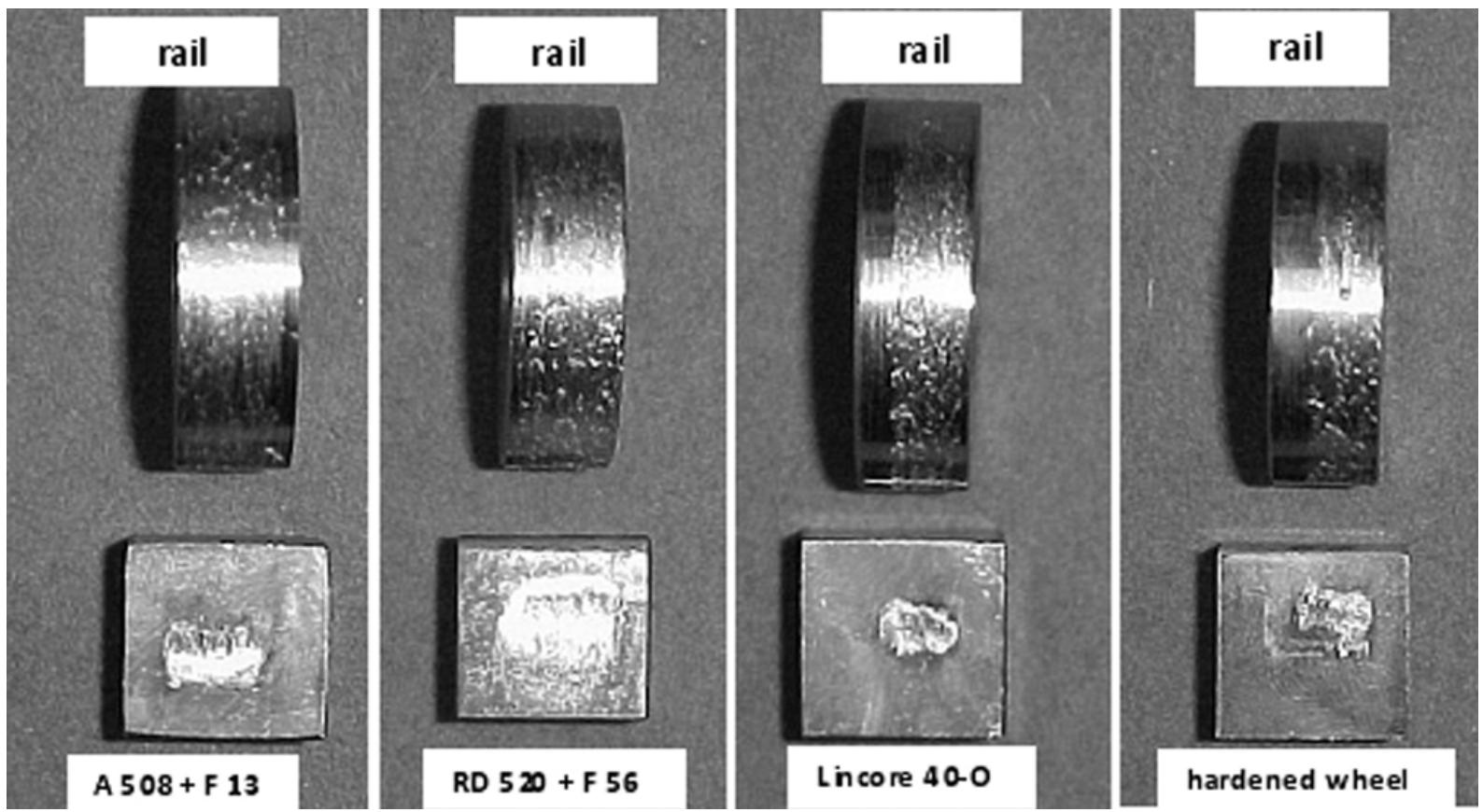

Figure 8. Friction pair - ring and plate after adhesive wear. 
through the interlayer up to cover layers corresponds to the type of used filling materials and mixing of the material in the layers. Analysis of microstructures shows that basic unaffected material is created by the ferriticpearlitic structure. After hardening the base material structure transformed into martensitic. In the first welding-on technology, in which the cover layer was hardened on the surface, the structure was bainitic. In the second welding-on technology, the cover layer was created by bainite. In the third technology, the cover layer was created by soft-grained acicular ferritic structure.

The highest hardness values showed the samples taken from new surface-hardened wheels ( $703 \mathrm{HV} 10$ or $780 \mathrm{HV}$ $0 \cdot 01$ ). Hardness and microhardness measured in samples taken from welds-on was one third lower than the values measured in samples from new wheels. Cross sections of the evaluated welds showed the influence of material mixing and heat treatment on hardness and microhardness.

Adhesive wear was examined on the laboratory machine, AMSLER. Testing samples were evaluated on the basis of weight differences as well as the time period till seizure of friction contact pairs. The obtained experimental results showed that the material structure and its chemical composition had a decisive influence on material resistance to the evaluated type of wear and tear. The highest resistance showed the samples taken from new surfacehardened wheels but the time until seizure of the friction pairs was the shortest. In samples taken from welds-on the best results were obtained in the weld-on with the cover layer made with Lincore $40-\mathrm{O}$ wire. This material showed the smallest weight losses and at the same time the longest times till seizure, wherein comparison with the surface-hardened layer of new wheels the time was twice as long as that.

Based on the obtained experimental results and analyses, the third welding-on technology, i.e. technology where the interlayer was made by GMAW technology with $\mathrm{C}$ 113 welding-on wire in protective atmosphere of mixed gases $\left(80 \% \mathrm{Ar}+20 \% \mathrm{CO}_{2}\right)$ and two cover layers were welded-on with welding-on wire with its own protection Lincore 40-O, could be considered the most suitable technology for renovation of worn-out traverse crane wheels. A certain drawback of the third welding-on technology is a sharp transition between cover layers, which will be necessary to eliminate in the future by preheating of each of the layers.

\section{References}

Bhansali K J 1980 Wear coefficients of hard surfacing material, in Wear control handbook (eds) M B Peterson and W O Winer (New York: ASME) pp 373-383

Kou S 2003 Welding metallurgy (New York: John Wiley and Sons) 2nd ed., p. 450

Limmaneevichitr C and Kou S 2000 Weld. J. 79324

Matsuda F, Ushio M, Nakagawa H and Nakata K 1980 Proceedings of conf. on arc physics and weld pool behaviour (Arbington Hall, Cambridge: Welding Institute) Vol. 1, p. 337 Viňáš J 2004 Acta Mech. Slovaca 3-b 209 